\title{
Head and body orientation of the White Stork Ciconia ciconia during incubation: effect of wind, apex predators and power lines
}

\author{
Adam Zbyryt $^{1}$ (D) $\cdot$ Łukasz Jankowiak $^{2}$ (D) $\cdot$ Leszek Jerzak $^{3}$ (D) $\cdot$ Piotr Tryjanowski $^{4,5}$ (D)
}

Received: 19 March 2021 / Revised: 13 July 2021 / Accepted: 21 July 2021 / Published online: 28 July 2021

(c) The Author(s) 2021

\begin{abstract}
Incubation behaviour is essential for understanding the reproductive success in birds. For example, the orientation of the bird is important for reducing incubation costs associated with wind or sun, but on the other hand can be modified by the perceived risk of predation. We studied the body position of incubating White Stork Ciconia ciconia in eastern Poland using a small unmanned aerial vehicle (drone). The head and body orientation of the incubating storks was non-random and modified by natural factors, mainly wind direction and speed, but also by the presence of an apex predator, the White-tailed Eagle Haliaeetus albicilla. However, head orientation during incubation in nests located on electricity poles was also modified by the presence of the power lines, probably due to disturbance in the magnetic field detected by birds. Surprisingly, although the positioning of incubating birds (mainly females) is very important for the detection of predators and for reducing energy costs, these have not previously been studied. New technologies, such as drones, make it possible to collect new, extensive information on the incubation behaviour of birds.
\end{abstract}

Keywords Apex predator · Incubation behaviour $\cdot$ Landscape of fear $\cdot$ Magnetic field detection $\cdot$ Unmanned aerial vehicle

\section{Zusammenfassung}

Kopf- und Körperausrichtung des Weißstorchs Ciconia ciconia während des Brütens: Auswirkungen von Wind, Stromleitungen und den wichtigsten Räubern

Das Verhalten während des Brütens ist für das Verständnis des Bruterfolgs von Vögeln essentiell. So ist zum Beispiel die Körperausrichtung eines Vogels wichtig, um die von Wind oder Sonne abhängigen Kosten des Brütens zu verringern, die andererseits auch durch das Risiko, von Raubtieren erbeutet zu werden, verändert werden. Wir untersuchten die Körperausrichtung brütender Weißstörche Ciconia ciconia in Ostpolen mit Hilfe eines kleinen unbemannten Luftfahrzeugs (einer Drohne). Die Kopf- und Körperausrichtung der brütenden Störche war nicht zufällig und wurde durch natürliche Faktoren verändert, hauptsächlich durch Windrichtung und -geschwindigkeit, aber auch durch die Anwesenheit ihres wichtigsten Feindes, des Seeadlers Haliaeetus albicilla. Allerdings wurde die Ausrichtung des Kopfes während der Brutzeit in Nestern, die sich auf Strommasten befanden, auch durch die Stromleitungen selbst verändert, wahrscheinlich durch eine Störung des von den Vögeln wahrgenommenen Erdmagnetfeldes. Obwohl die Körperausrichtung der brütenden Vögel

Communicated by F. Bairlein.

Piotr Tryjanowski

piotr.tryjanowski@gmail.com

Adam Zbyryt

adam.zbyryt@gmail.com

Łukasz Jankowiak

jankowiakl@gmail.com

Leszek Jerzak

1.jerzak@wnb.uz.zgora.pl

1 Faculty of Biology, University of Białystok, Ciołkowskiego 1J, 15-245 Białystok, Poland

2 University of Szczecin, Wąska 13, 71-412 Szczecin, Poland

3 Faculty of Biological Sciences, University of Zielona Gora, Szafrana 1, 65-516 Zielona Gora, Poland

4 Department of Zoology, Poznań University of Life Sciences, Wojska Polskiego 71C, 60-625 Poznan, Poland

5 Faculty of Environmental Sciences, Czech University of Life Sciences Prague, Kamýcká 129, 16500 Prague 6, Czech Republic 
(hauptsächlich Weibchen) sehr wichtig für die Erkennung von Räubern und für die Verringerung der Energiekosten ist, wurde dies überraschenderweise bisher nicht untersucht. Neue Technologien, wie z. B. Drohnen, machen es heutzutage möglich, neue und umfangreiche Informationen über das Brutverhalten von Vögeln zu sammeln.

\section{Introduction}

Incubation behaviour is central to the reproductive success of birds (Carey 1980; Deeming and Reynolds 2015). Incubating adults must ensure that eggs are kept within a relatively narrow temperature range to promote the growth of developing embryos (Carey 1980; Deeming and Reynolds 2015). Therefore, incubation should be, and is, modified by the behaviour of the adult birds depending on weather conditions (Weller 1958; Gochfeld 1978). A particularly influential factor on the body orientation of incubating birds is wind direction and its strength, substantially modifying the behaviour of birds, and in particular turning the head and body to reduce both air resistance and the energy costs of incubation (Poussart et al. 2001; Baoqing et al. 2004). Incubation is time-consuming and takes place in a practically stationary position, by adult birds, most often the female, sitting on the nest. Such a permanent, stationary position with limited visibility (Graham 2011) makes the incubating bird relatively safe from attack by a predator (Carey 1980; Bakner et al. 2019).

In contrast, the White Stork Ciconia ciconia is a species that builds large, open nests, very often on the top of manmade structures, and less often on trees, which are clearly visible against the skyline (Creutz 1988; Tryjanowski et al. 2009; Zbyryt et al. 2020). Incubation in this species takes 32 (29-34) days and usually starts with the second egg (Bocheński and Jerzak 2006; Wuczyński 2012). Both mates incubate, but the female contributes more than the male (Bocheński and Jerzak 2006; Kosicki 2010). The White Stork is a large species (after Creutz (1988) —body mass: $2.3-4.5 \mathrm{~kg}$, wing span: $155-215 \mathrm{~cm}$ ), but sometimes is the subject of attacks by large birds of prey. However, the White Stork has to fear only a few predators such as the White-tailed Eagle Haliaetus albicilla, the golden eagle Aquila chrysaetos and Bonelli's Eagle Hieraaetus fasciatus. These raptors in the vicinity of the nest always evoke a very strong reaction. Less often the appearance of smaller raptor species, such as the Common Buzzard Buteo buteo or female of the Northern Goshawk Accipiter gentilis, sometimes elicits the anxiety stretch display (Bocheński and Jerzak 2006). In Central and Eastern Europe, confirmed cases of predating storks, both young and adults, are known only by white-tailed eagles (Zawadzka et al. 2006; Dementavičius et al. 2020).

Recently, the White Stork has increased the proportion of nests located on electricity poles (Tryjanowski et al. 2009; Vaitkuviené and Dagys 2014), or even on special poles not connected to the power network (Kosicki 2010; Zbyryt et al.
2021). The flowing electrical current disturbs the reception of the magnetic field (Balmori 2015) and also affects the breeding parameters of birds, including the White Stork (Vaitkuviené and Dagys 2014). It is, therefore, possible to expect, by analogy with observations of grazing, resting or defecating mammals (Burda et al. 2009; Yosef et al. 2020), changes in the alignment of the incubating bird towards the North-South axis. This may be especially observable in sitting, incubating birds on electricity poles, because their head, where the magnetoreceptors are located (Mouritsen et al. 2004), is very close to wires with a flowing electrical current.

Additionally, the White Stork is an interesting species for checking the effect of various factors on incubation behaviour from a technical point of view. As mentioned above, storks build highly visible large nest platforms and incubating birds are easy to monitor, by unmanned aerial vehicles (drones) and it is possible to obtain a large sample size in a short period of time without disturbance (Zbyryt et al. 2020).

Therefore, the main aim of the study was to describe the body orientation of incubating birds during the daytime and to establish the influence of external factors, such as wind, predator presence, and nest location (electricity poles vs. other structures) on incubation behaviour. We suggest that this information may help in better understanding breeding behaviour, ecology and, in consequence, the population trajectory of the White Stork, which are especially important in light of new nesting sites (artificial poles) provided by conservationists, both in this particular area, as well as across the geographical range of the species (Muzinic 1999; Zbyryt et al. 2021).

\section{Materials and methods}

\section{Study site}

The research was conducted between May 17 and May 20, 2020 in north-eastern Poland. The largest population of White Storks in the country (Zbyryt et al. 2014, A. Zbyryt—unpublished data) occurs in this region.

\section{Fieldwork}

Data were collected using a small quadrocopter Phantom 4 (DJI, Shenzhen, China) with an in-built $12 \mathrm{Mp}$ camera (20 $\mathrm{mm}$ lens), coloured white. The detailed specification of this device is described by Zbyryt et al. (2020). 
Flights were made to 181 nests in which incubating storks were found: 81 were on electricity poles, 68 on free-standing poles, 23 on buildings and 9 on trees. All electricity poles with nests were connected to the low-voltage power grid $(0.4 \mathrm{kV})$, and those on trees were at their top and were not sheltered by branches. Each nest was recorded only once. Take-off was performed from a distance of at least $30 \mathrm{~m}$, as this has been shown to be a distance that does not cause disturbance of White Storks on nests (Zbyryt et al. 2020). An overhead photo was taken of each nest from a height of $40 \mathrm{~m}$ above the ground when the incubating bird was exactly in the central position of the monitor, which was helped by the arrangement of grid lines displayed on the screen of the MediaPad M3 tablet with a diagonal of 8.4" (Huawei, Shenzhen, China). Within one flight, between 1 and 17 nests were photographed (mean $=2.4 ; \mathrm{SD}=2.7$ ). Wind strength and direction were measured on an ongoing basis using the Meteo ICM-Numerical Weather Forecast application (University of Warsaw; www.meteo.pl), which was read for the nearest town for which weather data were given (no more than $15 \mathrm{~km}$ distant). The wind direction was verified in the field using a small flag and a compass built into a smartphone. During the survey period, we recorded winds only from three directions: WNW, NW, WSW and these categories were used in later analysis.

\section{Photo processing}

The orientation of the incubating bird (an axis along the bird's back and beak relative to north) was determined by means of a circular overlay on the photo in the form of a circle with an angular scale and auxiliary lines, made in vector graphics. The orientation of power lines was determined in the same way. Each electricity pole on which the nest was located had from 1 to 3 electrical lines (each of 3-5 parallel cables, Fig. 1) "connecting" under the nest. To determine the impact of breeding white-tailed eagles on the position of an incubating stork, data on the location of eagle nests in the area covered by the study was obtained from the database of the Eagle Conservation Committee. White-tailed eagles usually hunt within $4 \mathrm{~km}$ (range $2.5-15 \mathrm{~km}$ ) of their nest in the breeding season (Mizera 2015; Dementavičius et al. 2020). We assumed that these raptors could cause persistent reactions in storks nesting within this radius around the eagle nest, covering the area that eagles most frequently use (mentioned $4 \mathrm{~km}$ ). Assuming that the White-tailed Eagle would approach in a straight line from their nest, the storks nesting in raptor territory were classified into two categories: (1) with the eagle direction in the field of view, or (2) in the blind sector. The blind sector in the White Stork at the back of its head amounts to $72^{\circ}$ (Graham 2011) and we used this range in our study. The location and time of day of each nest image were read from the Exchangeable Image File Format.

\section{Statistical analysis}

We started our analysis by building the model with body orientation as the dependent variable. As independent variables we tested: Wind direction (three levels: WNW, NW, WSW), wind gusts (in meters per second, range 11-17), wind speed (metres per second, range 4-10), eagle presence (two levels: yes, no), nest type (four levels: electricity pole, free-standing pole, tree, building) and time of day. In total we analyzed 181 records.
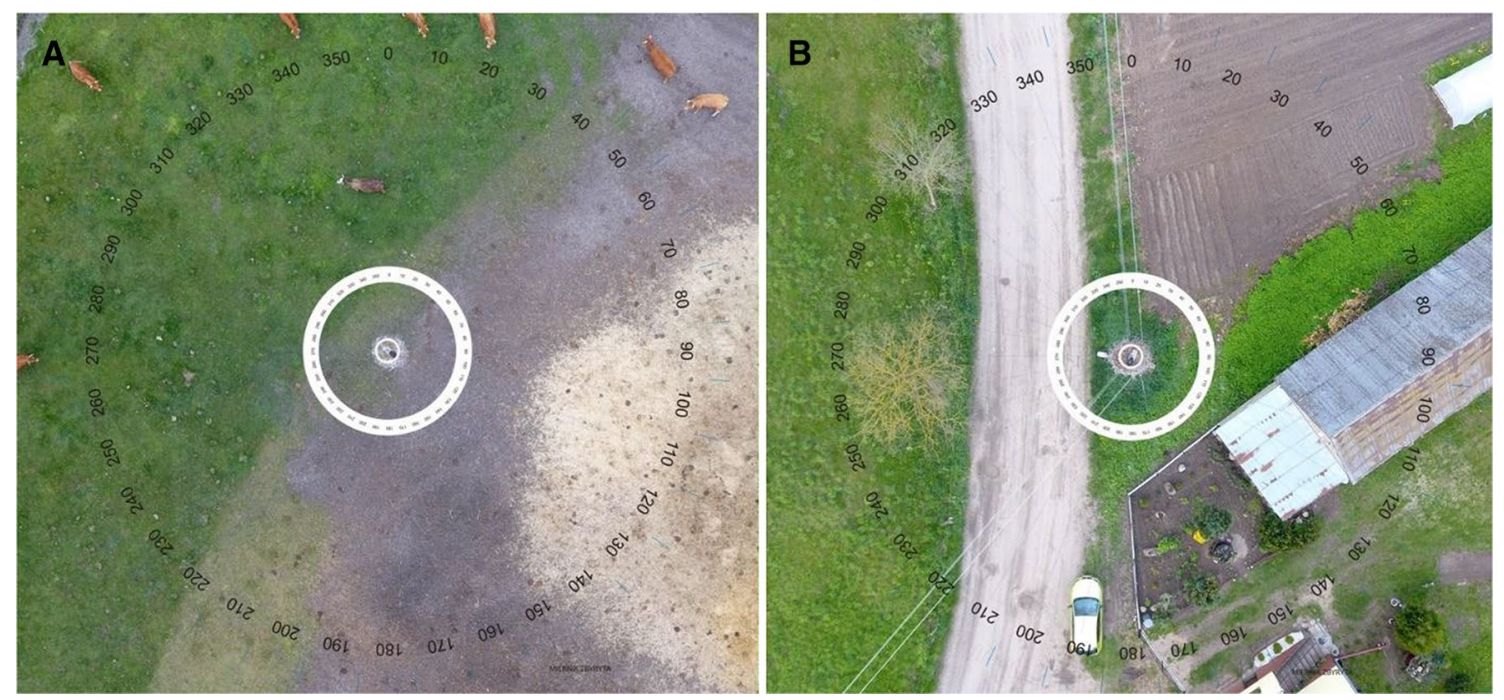

Fig. 1 Drone photos of nests and incubating storks. A grid with a graduated scale was overlaid on the photos. A Nest on a free-standing pole, B nest on a electricity pole with two connecting power lines which each consisted of two cables 
The orientations of the incubating birds are typical circular data whose main characteristic is the periodic nature $\left(0^{\circ}\right.$ is identical to $\left.360^{\circ}\right)$ that makes them fundamentally different from interval data which would treat the difference between $0^{\circ}$ and $360^{\circ}$ as $360^{\circ}$ (Cremers and Klugkist 2018). In our first approach, we used a projected normal circular general linear model (PN GLM) (Cremers and Klugkist 2018) which is a Bayesian method. To estimate model parameters we had to define parameters for the Markov Chain Monte Carlo (MCMC) algorithm (number of iteration, its $=10,000$; burn-in period, burn $=100$; lag, n.lag =3). All models were performed in the package bpnreg (Cremers 2018) in R software (R Development Core Team 2018). Circular plots were made in the package circular (Agostinelli and Lund 2017). We compared competing models using the deviance information criterion (DIC). A better fitting model is represented by lower values of DIC; two competing models can be compared where a difference $\geq 2$ DIC indicates a significantly better model.

For the subset of nests on electricity poles $(n=81)$ we wanted to analyze whether birds oriented themselves along power lines. The electrical lines consisted of 3 to 5 parallel cables, and further we did not distinguish a number of wires on each of the line, but we counted only the number of lines "connecting" under the nest (see Fig. 1B for an example of two lines of two cables each). Only 11 nests had one line, 40 had two lines, and 30 nests had three lines. In the latter two cases, we had to select one of the lines for line orientation. We chose this according to its closeness to the head of the bird, because the magnetic sensory organ is located in the head in migratory birds (Mouritsen et al. 2004; Heyers et al. 2007). However, the selection of the closest line could have biased our results, e.g. where there were 3 lines we selected that which was closest to the bird's head. To check this approach, we tested whether randomly generated bird orientations were correlated with the orientation of the selected line. If the randomly generated orientation was correlated with that of the selected lines it means that the observed correlation of bird orientation could be the result of chance not bird preference. To test it we used circular correlation (circular version of the Pearson's product-moment correlation in the package circular). The correlation between random bird orientations and those of power lines was not significant (Pearson's $r=0.004, t$-test $=0.04, P<0.970)$. Finally, we used the same statistical procedure as for the full data set. We compared the full model with lines as a new explanatory variable (M9 in Table 9) with the model without this variable (M10).

\section{Results}

The head orientation of the incubating storks was positioned in all compass directions (Fig. 2A) but were modified by external factors. The best model included wind direction, wind speed and eagle presence. We found that the type of nest did not have a significant effect on the bird's orientation (M1 vs M2). Wind direction significantly increased the fit of the model (M1 vs M5). If the wind was blowing from the NWW the mean orientation of the birds was $267^{\circ}$ and the mean resultant length $(0$ indicates that the spread of data points was very large, 1 indicates that the data were aggregated as a single value) was 0.56 (Fig. 2B). If the wind was blowing from the NW the mean orientation of the birds was $331^{\circ}$ and the mean resultant length was 0.45 (Fig. 2C). If the wind was blowing from the SWW the mean orientation of the birds was $166^{\circ}$ and the mean resultant length was 0.15 (Fig. 2D). Model parameters indicate that NWW was significantly different from NW and SWW. Further, the model fit decreased significantly (M5 vs M3) by adding the variable time of day. We found that the model with the variable gusts was a significantly better fit (M5 vs M6), however, by adding the variable wind speed (which was highly correlated with gusts; Spearman Rank Correlation $r_{\mathrm{s}}=0.64, P<0.001$ ) improved the model fit (M7 vs M5) so we included this variable in the final model. However, we did not find any circular coefficient of wind speed to be significant (highest posterior density interval of coefficient included zero); only the linear coefficient $(\beta=0.167 \pm 0.076 \mathrm{SD})$ was significant and it can be interpreted that increased wind speed increased the radius of the bird orientation (birds aligned more north-south). The fit of the model significantly increased (M8 vs M7) by adding eagle presence. However, there was no difference between the estimated circular means. This is due to a different spread of data points; if an eagle was not present (Fig. 3A) the mean orientation was $287^{\circ}$ and the mean resultant length was 0.74 . If an eagle was present (Fig. 3B) the mean orientation was $298^{\circ}$ and the mean resultant length was 0.24 which indicates a high spread of data points.

In the second data set where the lines variable was added we found that this model was significantly better than without (M9 vs M10; Table 1). However, the proposed projected normal circular general linear model (PN GLM) did not account for the circular-circular relation. To show the relationship we performed a simple circular correlation. The correlation between bird orientations and those of power lines was statistically significant (Pearson's $r=0.606$, $t$-test $=5.54, P<0.001)$ and can be interpreted as birds aligning with the power lines (Fig. 4). 
Fig. 2 Body orientation of White Storks on nests. Panel A shows all data. Panels B-D indicate the orientation of birds under different wind directions

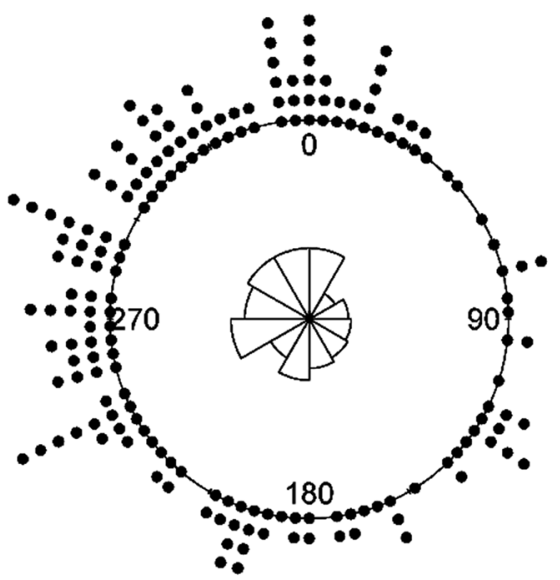

A All data

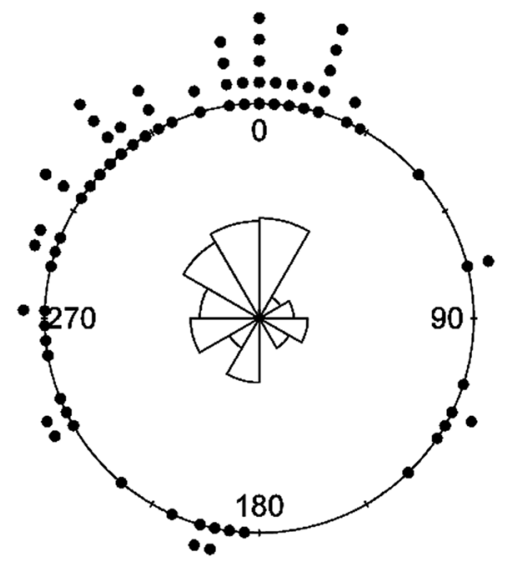

C Wind direction:NW

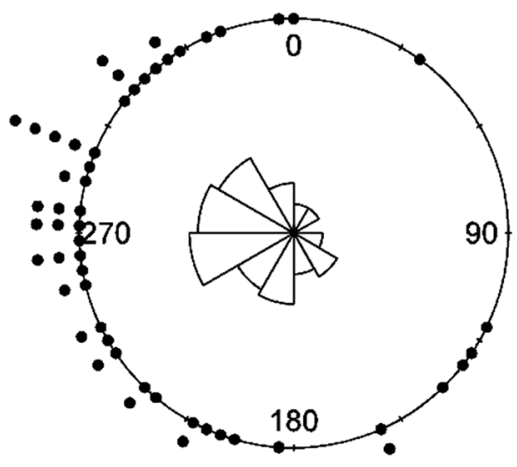

B Wind direction:NWW

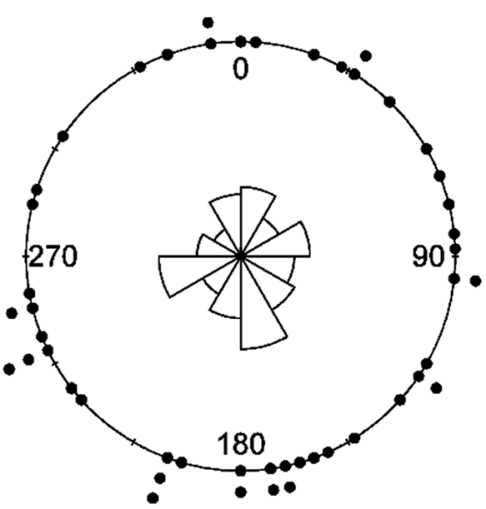

D Wind direction:SWW

\section{Discussion}

Given the fact that the White Stork is a well-studied species, it is surprising that the phenomenon we have examined had not previously been investigated. The results of our studies, although it may seem in some cases to be quite obvious, have interesting behavioural and conservation implications, as discussed below.

The head and body orientation of the incubating storks was non-random. As expected, several factors modified it. The strongest effect was caused by the prevailing wind, and depending on its strength and direction, the birds aligned their head and body in such a way as to provide the least possible air resistance, taking aerodynamic positions, as has also been shown in other species, e.g. the Common Tern Sterna hirundo (Gochfeld 1978), the Greater Snow Goose Chen caerulescens atlantica (Poussart et al. 2001), all species nesting on exposed sites, where winds can be particularly severe. This phenomenon must be very common among White Storks, considering that they nest on elevated structures in an open landscape. Such behaviour must be adaptive to such conditions, the more so since the stork's nest is quite flat and does not provide protection against the wind. This is confirmed by opportunistic observations made by the authors and other stork researchers, but this phenomenon has been described here for the first time. However, that aerodynamic position is probably also more common for birds using cup-nests located in exposed places, such as the top of trees, buildings or electricity poles (e.g. ospreys, vultures, white-tailed eagles, ravens).

In our research, we also showed that the orientation of the incubating female (predominantly) can be modified by the appearance of an apex predator, in this case, the White-tailed Eagle (Dementavičius et al. 2020). We see some limitations in the results of our research. An incubating bird does not need to see the incoming predator quickly, but its effect is noticed by other storks, including the partner and is communicated by a specific nervous behaviour (Jakubiec and Peterson 2005; Bocheński and Jerzak 2006). Individuals living in high densities do not have to constantly react to 
Fig. 3 Body orientation of White Storks on nests when eagle was not present $(\mathbf{A})$ or present (B)

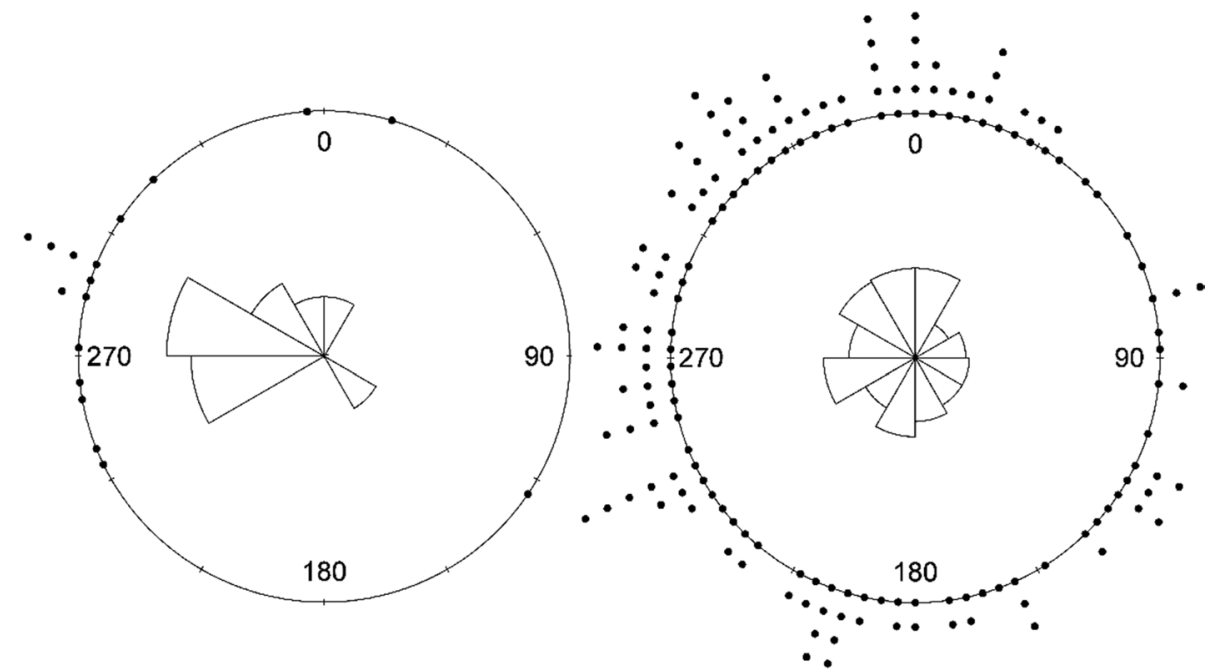

A Eagle: no
B Eagle: yes
Table 1 Comparison of fit of different models

\begin{tabular}{clcc}
\hline $\mathrm{Nr}$ & Model & DIC & Parameters \\
\hline $\begin{array}{c}n=181 \\
\text { M8 }\end{array}$ & $\begin{array}{c}\text { Wind.direction + Wind_ } \\
\text { speed + Eagle }\end{array}$ & 592.361 & 10.000 \\
& Wind.direction + Wind_speed & 597.490 & 7.890 \\
M7 & Wind.direction + Gusts & 599.565 & 7.905 \\
M6 & Wind.direction & 601.588 & 6.104 \\
M5 & Nest.type.+Wind.direction & 601.604 & 11.941 \\
M4 & 604.576 & 7.935 \\
M3 & Wind.direction + Time_day & 639.492 & 2.009 \\
M1 & Intercept & 642.100 & 7.959 \\
M2 & Nest.type & & \\
$n=71$ & & 263.3948 & 11.862 \\
M9 & Wind.direction + Wind_ & & \\
& speed + Eagle + Electrical_lines & 271.145 & 9.9467 \\
M10 & Wind.direction + Wind_ & & \\
& speed +Eagle & 297.657 & 1.988 \\
\hline
\end{tabular}

$D I C$ deviance information criterion

the threat from the predator when other factors come into play constantly (e.g. wind). They can be based on the manyeyes hypothesis, which assumes that the cost of scanning the environment is spread over many individuals (Lima 1995). The predator can approach from different directions, so it is difficult to expect a directional reaction, and the incubating bird has only a limited field of view (Graham 2011), so the body layout of the incubating female was also modified by other factors such as the wind direction (which interacts constantly and permanently). However, at least a few cases are known from the study area of the attack and direction of attack of white-tailed eagles on storks in the nests. The raptor came in a straight line from their nest site, grabbed the adult or chick and returned in a straight line to their nest.
The situation was repeated until all the chicks were predated (A. Zbyryt—unpublished data). This is rather unsurprising, taking into account the fact that the nests of White Storks are clearly visible and often function for decades in one place. Raptors can easily learn their location, distribution, occupation or breeding stage. This would also confirm our methodological assumption of how eagles depredated storks in their nests. In our study, the occupied nests that were within the range of the White-tailed Eagle were highly dispersed. We do not know if it is an effect of raptor pressure or a feature of the local population of White Storks. However, in this case, we can assume that storks have to rely on their own risk assessment or possibly their partner when he is near the nest. Storks usually forage within one $\mathrm{km}$ around the nest (Dziewiaty 1992; Alonso et al. 1994; Ożgo and Bogucki 1999), but in search of food they can fly up to $5 \mathrm{~km}$, which depends on agricultural activity (Johst et al. 2001). Therefore, in conditions of increased predation pressure, the reliance on the partner as an additional source of threat detection is very limited. Then the incubating female may turn her head more often to widen the field of view. The problem, however, is how often this should be done to avoid being caught off guard by the eagle. Under such conditions, such behaviour can lead to increased stress (Boonstra 2013). To reduce it, the incubating female can arrange her body in such a way as to be able to constantly monitor the area from which a predator may likely come. We believe that it is the much higher cost associated with the stress caused by the predator (a permanent factor) that contributes to the fact that an incubating stork responds more often with an appropriate body position in response to this factor than the negative impact of the wind (an occasional factor). Hence, it seems to us that the result obtained by us shows the real effect of shaping a new behavioural response to predatory pressure. 
Fig. 4 Orientation of White Storks (A) and of power lines (B)

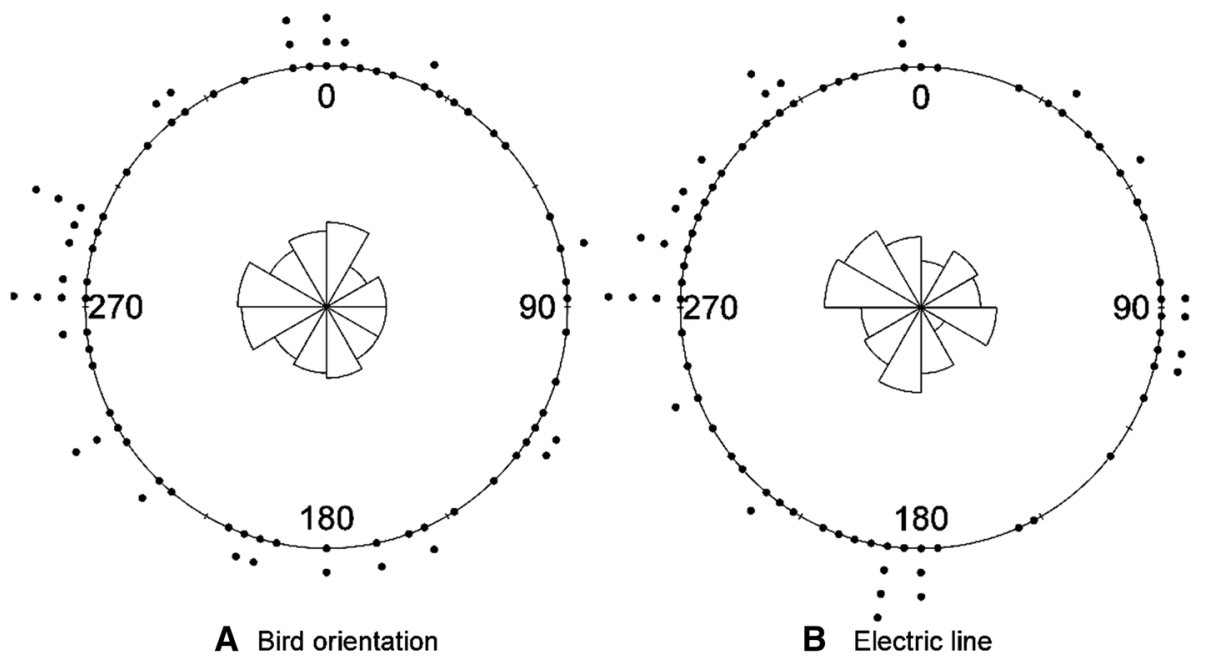

This also opens up an interesting area for discussion of how two endangered bird species, each of which is targeted with practical conservation assistance (Treinys et al. 2011), affect one another. The growing population of White-tailed Eagle in central and eastern Europe is already provoking discussions about the impact on other birds of prey and on the black stork Ciconia nigra (Zawadzka et al. 2006; Treinys et al. 2011). A similar effect is now also shown in the White Stork (Dementavičius et al. 2020), a species nesting in human settlements and traditionally considered a species under low predatory pressure (Creutz 1988; Kosicki 2010). Perhaps, however, this low level of pressure has only been a feature of the last few decades, when birds of prey were persecuted and therefore their impact on stork populations was not apparent. However, from a historical and evolutionary point of view, the trophic relations (predator (eagle) prey (stork)) are probably very old and are still documented in Africa (Parsons 1977). In the case of the population we studied and nearby, we have evidence that white-tailed eagles hunt White Storks (Dementavičius et al. 2020), from occasional observations by ornithologists to photos of the raptors' prey from their nests, where photo traps have been installed. The study of the food composition of the Whitetailed Eagle in the area of our study showed that the White Stork (mostly adults) is an important component of the raptor's diet-it was found in half of the nests. White stork was second in food composition in terms of biomass after Common Carp (Cyprinus carpio). White-tailed eagles hunt for storks mainly in spring, i.e. in the period that overlaps with the period of incubation of eggs by White Storks (Komar and Mirski 2019).

This also shows the formation of a "landscape of fear" among the local stork population-birds, despite the lack of direct exposure to attack, begin to modify their behaviour to avoid predator attack (Beauchamp 2017). Future research is needed to understand how common this phenomenon is, how it is learned to avoid predators, and how this information is spread between individuals (Berger 2001). The fact that only birds in the immediate vicinity of the White-tailed Eagle react may indicate that this is a very local phenomenon, limited to specific pairs and other individuals nesting within their visual range. Storks are strongly attached to their nests, which may limit the transfer of such knowledge if they do not live in high density.

Many animals tend to align their body axes in the geomagnetic North-South direction (Burda et al. 2009; Yosef et al. 2020). In the case of a long process of incubating eggs by storks, magnetic alignment could be expected, due to the fact that birds, especially long-distance migrants, have the ability to detect the Earth's magnetic field (Wiltschko and Wiltschko 1996; Heyers et al. 2007). However, we did not notice this phenomenon, but we have found other interesting issues that the low-voltage power lines influence the positioning of the bird's body on the nest. Electrical power lines generate an alternating magnetic field. It has been proven so far that productivity is the lowest in White Stork nests located directly on low-voltage power lines. The effect was stronger the closer the nest was to the wires (Vaitkuviene and Dagys 2014). The explanation for why incubating birds align their heads to power lines may be related to the fact that migratory birds use their visual system to perceive the reference compass direction of the geomagnetic field. In other words, migratory birds, which include the White Stork, "see" the reference compass direction provided by the geomagnetic field (Heyers et al. 2007). It is true that the birds did not migrate at the time of or study, but this ability must be permanent and somehow cause a strong behavioural response of storks to this phenomenon. In our case, the alignment also had a stronger effect, as in terms of breeding parameters (Vaitkuviené and Dagys 2014). This also shows how complex and multifaceted the impact of eclectic smog on animals is (Balmori 2015). 
Finally, it is also worth noting that the orientation during incubation in conditions of greater population density, that is, in the case of colony nesting of the White Stork (Turjeman et al., 2016) could be further modified, at least at the beginning of incubation when females are still in their fertile period, by the desire to guard the partner and thus avoid extra-pair copulations. However, this would require research in colonies of this species, for example on the Iberian Peninsula or in northern Poland (e.g. Cabodevilla and Aguirre 2019; Zbyryt et al. 2014). In our case, it did not matter, because to avoid this effect, we carried out our research in a narrow time window in the final phase of egg incubation, just before hatching of the first chicks.

Acknowledgements We would like to thank Tim H. Sparks and Zbigniew Kwieciński for constructive comments on the first version of the manuscript.

\section{Declarations}

Conflict of interest The authors declare no conflicts of interest.

Ethical statement No bird was disturbed or injured during the experiment. We confirm that the procedures used in the study were in accordance with Polish law (license PL.39050.UAV).

Open Access This article is licensed under a Creative Commons Attribution 4.0 International License, which permits use, sharing, adaptation, distribution and reproduction in any medium or format, as long as you give appropriate credit to the original author(s) and the source, provide a link to the Creative Commons licence, and indicate if changes were made. The images or other third party material in this article are included in the article's Creative Commons licence, unless indicated otherwise in a credit line to the material. If material is not included in the article's Creative Commons licence and your intended use is not permitted by statutory regulation or exceeds the permitted use, you will need to obtain permission directly from the copyright holder. To view a copy of this licence, visit http://creativecommons.org/licenses/by/4.0/.

\section{References}

Agostinelli C, Lund U (2017) R package “circular”: Circular Statistics (version 0.4-93)

Alonso JA, Alonso JC, Carrascal LM, Munoz-Pulido R (1994) Flock size and foraging decisions in central place foraging White Storks, Ciconia ciconia. Behaviour 129:279-292. https://doi.org/10.1163/ $156853994 X 00640$

Bakner NW, Schofield LR, Cedotal C, Chamberlain MJ, Collier BA (2019) Incubation recess behaviors influence nest survival of Wild Turkeys. Ecol Evol 9:14053-14065. https://doi.org/10. 1002/ece3.5843

Balmori A (2015) Anthropogenic radiofrequency electromagnetic fields as an emerging threat to wildlife orientation. Sci Total Environ 518:58-60. https://doi.org/10.1016/j.scitotenv.2015. 02.077

Baoqing L, Jun Z, Ainan Q (2004) Studies on incubation and raising of oriental White Stork (Ciconia boyciana). Chin J Zool 39:45-47
Beauchamp G (2017) What can vigilance tell us about fear? Anim Sentience 15:1

Berger J (2001) Recolonizing carnivores and naive prey: conservation lessons from pleistocene extinctions. Science 291(5506):10361039. https://doi.org/10.1126/science. 1056466

Bocheński M, Jerzak L (2006) Behaviour of the White Stork: a review. In: Tryjanowski P, Sparks TH, Jerzak L (eds) The White Stork in Poland: studies in biology, ecology and conservation (pp 295324). Bogucki Wyd Nauk Poznań

Boonstra R (2013) Reality as the leading cause of stress: rethinking the impact of chronic stress in nature. Funct Ecol 27:11-23. https:// doi.org/10.1111/1365-2435.12008

Burda H, Begall S, Červený J, Neef J, Němec P (2009) Extremely lowfrequency electromagnetic fields disrupt magnetic alignment of ruminants. Proc Natl Acad Sci 106:5708-5713. https://doi.org/10. 1073/pnas.0811194106

Cabodevilla X, Aguirre JI (2019) The nesting synchronisation process of new breeders in a White Stork Ciconia ciconia colony. Ardeola 66:279-289. https://doi.org/10.13157/arla.66.2.2019.ra2

Carey C (1980) The ecology of avian incubation. Bioscience 30:819824. https://doi.org/10.2307/1308374

Cremers J (2018) Bpnreg: Bayesian projected normal regression models for circular data. R Package Version 1:3. https://doi.org/10. 3389/fpsyg.2018.02040

Cremers J, Klugkist I (2018) One direction? A tutorial for circular data analysis using $\mathrm{R}$ with examples in cognitive psychology. Front Psychol 9:1-13

Creutz G (1988) Der Weissstorch: Ciconia ciconia (vol. 375). Ziemsen

Deeming DC, Reynolds SJ (eds) (2015) Nests, eggs, and incubation: new ideas about avian reproduction. Oxford University Press, USA

Dementavičius D, Rumbutis S, Virbickas T, Vaitkuvienė D, Dagys M, Treinys R (2020) Spatial and temporal variations in the Whitetailed Eagle Haliaeetus albicilla breeding diet revealed by prey remains. Bird Study 67:1-11. https://doi.org/10.1080/00063657. 2020.1808591

Dziewiaty K (1992) Nahrungsökologische Untersuchungen am Weißstorch Ciconia ciconia in der Dannenberger Elbmarch (Niedersachsen). Vogelwelt 113:133-144

Gochfeld M (1978) Incubation behaviour in common terns: influence of wind speed and direction on orientation of incubating adults. Anim Behav 26:848-851

Graham RM (2011) Understanding bird collisions with man-made objects: a sensory ecology approach. Ibis 153:239-254. https:// doi.org/10.1111/j.1474-919X.2011.01117.X

Heyers D, Manns M, Luksch H, Güntürkün O, Mouritsen H (2007) A visual pathway links brain structures active during magnetic compass orientation in migratory birds. PLoS ONE 2:e937. https://doi. org/10.1371/journal.pone.0000937

Jakubiec Z, Peterson U (2005) Relationship between white-tailed eagle Haliaeetus albicilla and white stork Ciconia ciconia. Buteo 14:51-52

Johst K, Brandl R, Pfeifer R (2001) Foraging in a patchy and dynamic landscape: human land use and the white stork. Ecol Appl 11:6069. https://doi.org/10.1890/1051-0761(2001)011[0060:FIAPAD] 2.0.CO;2

Komar E, Mirski P (2019) White stork in white-tailed diet. In: International conference on the protection of the white stork. PTOP and White Stork Research Group, November, Grzedy, Poland

Kosicki JZ (2010) Reproductive success of the white stork Ciconia ciconia population in intensively cultivated farmlands in western Poland. Ardeola 57:243-255

Lima SL (1995) Back to the basics of anti-predatory vigilance: the group-size effect. Anim Behav 49:11-20. https://doi.org/10.1016/ 0003-3472(95)80149-9 
Mizera T (2015) White-tailed eagle Haliaeetus albicilla. In: W: Chylarecki P, Sikora A, Cenian Z, Chodkiewicz T (eds) Monitoring of breeding birds. Methodical guide. $2^{\text {nd }}$ Edition. IEP, Warsaw pp 431-437 (in Polish)

Mouritsen H, Feenders G, Liedvogel M, Kropp W (2004) Migratory birds use head scans to detect the direction of the Earth's magnetic field. Curr Biol 14:1946-1949. https://doi.org/10.1016/j.cub.2004. 10.025

Muzinic J (1999) A frame for white stork nests. Isr J Zool 45:497-499

Ożgo M, Bogucki Z (1999) Home range and intersexual differences in the foraging habitat use of a White Stork (Ciconia ciconia) breeding pair. In: Schulz H (ed) Weißstorch im Aufwind?-White Storks on the up? Proc Int Symp White Stork, Hamburg, 1996, NABU, (Naturschutzbund Deutchland e. V.), Bonn, pp 481-492

Parsons J (1977) The effect of predation by Fish Eagles on the breeding success of various Ciconiiformes nesting near Kisumu, Kenya. J Nat Hist 11:337-353

Poussart C, Gauthier G, Larochelle J (2001) Incubation behaviour of greater snow geese in relation to weather conditions. Can J Zool 79:671-678. https://doi.org/10.1139/z01-023

R Development Core Team (2018) R: A language and environment for statistical computing. R Foundation for Statistical Computing, Vienna, Austria

Treinys R, Dementavičius D, Mozgeris G, Skuja S, Rumbutis S, Stončius D (2011) Coexistence of protected avian predators: does a recovering population of White-tailed Eagle threaten to exclude other avian predators? Eur J Wildl Res 57:1165-1174. https://doi. org/10.1007/s10344-011-0529-7

Tryjanowski P, Kosicki JZ, Kuźniak S, Sparks TH (2009) Long-term changes and breeding success in relation to nesting structures used by the white stork, Ciconia ciconia. Ann Zool Fenn 46:34-38. https://doi.org/10.5735/086.046.0104

Turjeman SF, Centeno-Cuadros A, Eggers U, Rotics S, Blas J, Fiedler W, Kaatz M, Jeltsch F, Wikelski M, Nathan R (2016) Extra-pair paternity in the socially monogamous white stork (Ciconia ciconia) is fairly common and independent of local density. Sci Rep 6:27976. https://doi.org/10.1038/srep27976
Vaitkuvienė D, Dagys M (2014) Possible effects of electromagnetic field on White Storks Ciconia ciconia breeding on low-voltage electricity line poles. Zool Ecol 24:289-296. https://doi.org/10. $1080 / 21658005.2014 .962783$

Weller MW (1958) Observations on the incubation behavior of a Common Nighthawk. Auk 75:48-59

Wiltschko W, Wiltschko R (1996) Magnetic orientation in birds. J Exp Biol 199:29-38

Wuczyński A (2012) Prolonged incubation and early clutch reduction of White Storks (Ciconia ciconia). Wilson J Ornithol 124:362366. https://doi.org/10.1676/11-154.1

Yosef R, Michal R, Ben-Baruch N, Shmueli L, Kosicki JZ, Fratczak M, Tryjanowski P (2020) Directional preferences of dogs' changes in the presence of a bar magnet: educational experiments in Israel. J Vet Behav 35:34-37. https://doi.org/10.1016/j.jveb.2019.10.003

Zawadzka D, Zawadzki J, Sudnik W (2006) Population development, habitat requirements and ecology of the White-tailed Eagle Haliaeetus albicilla in the Augustów Forest. Not Orni 47:217-229 (in Polish with English abstract)

Zbyryt A, Menderski S, Niedźwiecki S, Kalski R, Zub K (2014) White Stork Ciconia ciconia breeding population in Warmińska Refuge (Natura 2000 Special Protection Area). Ornis Pol 55:240-256 (in Polish with English abstract)

Zbyryt A, Dylewski Ł, Morelli F, Sparks TH, Tryjanowski P (2020) Behavioural responses of breeding white storks Ciconia ciconia to an unmanned aerial vehicle. Acta Ornithol 55(2):243-251. https:// doi.org/10.3161/00016454AO2020.55.2.009

Zbyryt A, Sparks TH, Tryjanowski P (2021) Whitewashing improves relocated nest occupancy in the white stork: an experimental test of public information. J Nat Conserv 59:125929. https://doi.org/ 10.1016/j.jnc.2020.125929

Publisher's Note Springer Nature remains neutral with regard to jurisdictional claims in published maps and institutional affiliations. 